\title{
Variceal Bleeding: Pharmacological Therapy
}

\author{
Jaime Bosch Juan G. Abraldes \\ Hepatic Hemodynamics Laboratory, Liver Unit, IMD, Hospital Clinic, IDIBAPS, University of Barcelona, \\ Barcelona, Spain
}

\section{Key Words}

Portal hypertension · Beta-adrenergic blockers .

Cirrhosis

\begin{abstract}
The complications of portal hypertension are totally prevented if hepatic venous pressure gradient is decreased below $12 \mathrm{~mm} \mathrm{Hg}$. Besides, if this target is not achieved, a $20 \%$ decrease in portal pressure from baseline levels offers an almost total protection from variceal bleeding. This sets the rationale for drug therapy to reduce portal pressure in portal hypertension. Pharmacological therapy to decrease portal pressure includes vasoconstrictors to decrease portal blood inflow, vasodilators to decrease hepatic resistance, and combination therapy. Oral agents, such as $\beta$-adrenergic blockers and organic nitrates, are used for long-term prevention of variceal bleeding, while parenteral agents, such as somatostatin (and analogues) and terlipressin, are used for the treatment of acute variceal bleeding.
\end{abstract}

Copyright $\odot 2005$ S. Karger AG, Basel

\section{Rational Basis of Drug Therapy for Portal Hypertension}

Portal hypertension, i.e. an increase in portal pressure above a critical threshold, is the major cause of complications and is thus clinically significant. This very important concept has been strongly substantiated in recent years. Hepatic venous pressure gradient (HVPG) [1], which accurately reflects portal pressure in the majority of liver diseases [2,3], is the most commonly used method to assess portal pressure in clinical practice. Varices do not develop until the HVPG increases to 10-12 mm $\mathrm{Hg}$, and the HVPG should be of at least $12 \mathrm{~mm} \mathrm{Hg}$ for the appearance of other complications, such as variceal bleeding and ascites [4-6]. Implicit in this concept is that preventing the HVPG to increase above these values, will prevent the development of the complications of portal hypertension. The question that follows is if by reducing the HVPG below these thresholds, complications of portal hypertension could be prevented. Indeed longitudinal studies have demonstrated that if HVPG decreases below $12 \mathrm{~mm} \mathrm{Hg}$ by means of pharmacological treatment [7, 8] or spontaneously due to an improvement in liver disease [9], variceal bleeding is totally prevented and varices may decrease in size. Besides, if this target is not achieved, a substantial decrease in portal pressure from baseline levels offers an almost total protection from variceal bleed- 
ing. This 'substantial' decrease in baseline HVPG needed to achieve protection was found to be of at least $20 \%$ [8], a finding confirmed in a number of subsequent studies [10-15]. This reduction in the HVPG of more than $20 \%$ and/or a reduction below $12 \mathrm{~mm} \mathrm{Hg}$ are now accepted as the therapeutic targets in the treatment of portal hypertension. Moreover, the achievement of these targets may be associated with a lower risk of developing ascites, spontaneous bacterial peritonitis, hepatorenal syndrome and death [14], thus demonstrating the reversibility of the portal hypertensive syndrome by means of pharmacological therapy. Additionally, in patients with acute variceal bleeding, an HVPG $>20 \mathrm{~mm} \mathrm{Hg}$ measured within $48 \mathrm{~h}$ after admission is the strongest indicator of treatment failure [16-18], suggesting that portal pressure reducing agents may improve the prognosis in this setting. These findings provide the rationale for treatments aimed to reduce portal pressure in patients with portal hypertension.

A basic knowledge of the pathophysiology of portal hypertension is required to understand the pharmacological treatment of portal hypertension. Experimental studies have shown that the initial factor in the pathophysiology of portal hypertension is the increase in vascular resistance to portal blood flow. In cirrhosis this increase in resistance occurs at the hepatic microcirculation (sinusoidal portal hypertension). It is important to emphasize that, in contrast to what was traditionally thought, increased hepatic vascular resistance in cirrhosis is not only a mechanical consequence of the hepatic architectural disorder caused by the liver disease, but there is also a dynamic component, due to the active contraction of portal/septal myofibroblasts, activated hepatic stellate cells and vascular smooth muscle cells in portal venules [19-21]. This increase in the intrahepatic vascular tone is modulated by the increased activity of endogenous vasoconstrictors such as endothelin, $\alpha$-adrenergic stimulus, leukotrienes, thromboxane $\mathrm{A}_{2}$, angiotensin II and others [21-24], and is lessened by nitric oxide (NO), prostacyclin and many vasodilating drugs (organic nitrates, adrenolytic agents, and calcium channel blockers) [25-27]. In cirrhosis, hepatic vascular resistance is increased because of an imbalance between vasodilator and vasoconstrictor stimuli, the former being insufficient to counteract the influence of the latter [19]. Indeed, in cirrhosis these vasoconstrictors are increased, whilst intrahepatic NO production is clearly decreased [19, 28, 29]. This deficient intrahepatic NO production is the result of an endothelial dysfunction in the liver microvasculature [28, 29], and may also favor local thrombosis and fibrogenesis [19].
This provides a rational basis for using NO-based therapies in the treatment of portal hypertension.

A second factor contributing to portal hypertension is an increase in blood flow through the portal venous system due to splanchnic arteriolar vasodilatation. This is caused by an excessive release of endogenous vasodilators (endothelial and neuro-humoral) [30-34]. Splanchnic hyperemia contributes to aggravate the increase in portal pressure and explains why portal hypertension persists despite the establishment of an extensive network of porto-systemic collaterals that may divert over $80 \%$ of the portal blood flow. The increased portal venous inflow can be corrected pharmacologically by means of splanchnic vasoconstrictors such as vasopressin and its derivatives, somatostatin and its analogues and nonselective $\beta$-adrenergic blockers, which are the drugs that have been more widely used in the treatment of portal hypertension. Splanchnic vasodilatation is in part due to an increased release of NO, which is amenable to pharmacological manipulation. However, this faces the difficulty of inhibiting NO synthesis only in the splanchnic circulation, which is not feasible at present.

Splanchnic vasodilatation is accompanied by an increased cardiac index and hypervolemia, representing the hyperkinetic circulatory syndrome associated with portal hypertension $[35,36]$. An expanded blood volume is necessary to maintain the hyperdynamic circulation, which provides a rationale for the use of a low-sodium diet and spironolactone to attenuate the hyperkinetic syndrome and the portal pressure elevation in patients with cirrhosis [37].

Combined pharmacological therapy attempts to enhance the reduction of portal pressure by associating vasoconstrictive drugs, which act by decreasing portal blood inflow, and vasodilators, which reduce the intrahepatic vascular resistance [38] (fig. 1).

\section{Pharmacological Treatment of Portal Hypertension}

The treatment of portal hypertension includes the prevention of variceal hemorrhage in patients who have never bled, the treatment of the acute bleeding episode and the prevention of rebleeding in patients who have survived a bleeding episode from esophageal or gastric varices. An additional scenario may be suggested: the 'preprimary' prophylaxis, or treatment of compensated patients in order to prevent the development of varices and ascites. Orally active drugs are used for continuous phar- 
Fig. 1. Rational basis of the pharmacological therapy of portal hypertension. The initial factor that leads to portal hypertension is an increase in hepatic resistance. The recognition of a functional and, thus, reversible component in the increased hepatic resistance set the rationale for the use of vasodilators in portal hypertension. On the other hand, portal hypertension leads to a cascade of disturbances in the splanchnic and systemic circulation characterized by vasodilation, sodium and water retention and plasma volume expansion, that lead to an increase in portal blood inflow that contributes to maintain and aggravates portal hypertension. This sets the rationale for the use of vasoconstrictors and diuretics in the treatment of portal hypertension.

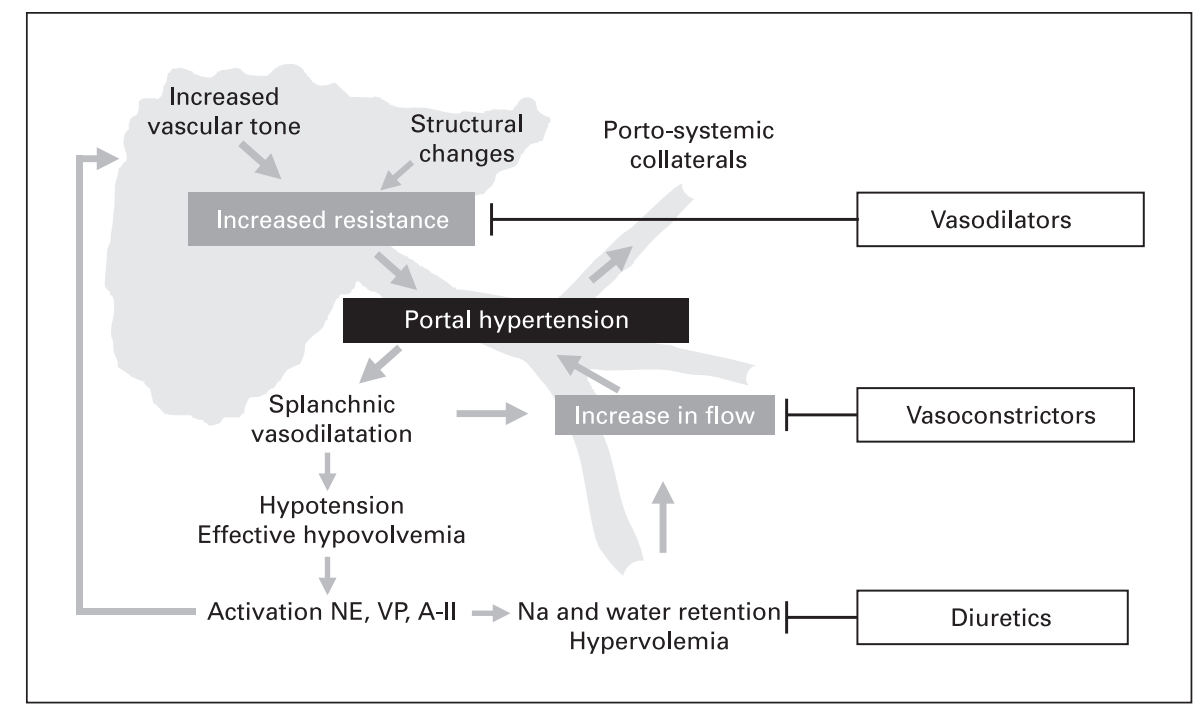

macological treatment to prevent bleeding, while parenterally administered drugs are used for the treatment of the acute bleeding episode.

\section{Pharmacological Treatment of the Acute Bleeding Episode}

Variceal bleeding is a medical emergency that should be managed in an intensive care setting by an experienced medical team, including well-trained nurses, clinical hepatologists, endoscopists and surgeons. The initial therapy is aimed at correcting hypovolemic shock, with judicious volume replacement and transfusion, preventing complications associated with gastrointestinal bleeding, and achieving hemostasis at the bleeding site. The two first goals, which are independent of the cause of the hemorrhage, demand immediate management. Specific therapy to stop bleeding is usually given when the patient has had the initial resuscitation and following diagnostic endoscopy, with the important exception of pharmacological therapy, that can be started earlier in the course of the bleeding episode.

\section{Antibiotics}

Infection is a strong prognostic indicator in acute variceal bleeding, both for rebleeding and mortality $[39,40]$. Antibiotic prophylaxis has been shown to reduce the risk of rebleeding [41] and mortality in acute variceal bleeding [42]. Antibiotic prophylaxis should be instituted from admission and the presence of infection should be inves- tigated. Norfloxacin, $400 \mathrm{mg} / 12 \mathrm{~h}$, is the first-choice antibiotic prophylaxis due to its simpler administration and lower cost [43]. In high-risk patients (hypovolemic shock, ascites, deteriorated liver function) intravenous ceftriaxone has recently been shown to be better than oral norfloxacin in a randomized trial [Fernandez et al., pers. commun.].

\section{Recombinant Activated Factor VIIa}

Only recently have clinical studies addressed the role of coagulopathy in the outcome of acute variceal bleeding or possible benefits from its correction. Preliminary data suggest that recombinant activated factor VII (rFVIIa, Novoseven), which corrects prothrombin time in patients with cirrhosis [44], significantly improves the results of conventional therapy in patients with Child-Pugh class B or $\mathrm{C}$ cirrhosis, without increasing the incidence of adverse effects [45] (fig. 2).

\section{Drugs to Stop Bleeding}

Vasopressin was the first drug used, but was abandoned 25 years ago because of the severity of its cardiovascular adverse events. The association of vasopressin infusion ( $0.4 \mathrm{U} / \mathrm{min}$ for $48 \mathrm{~h}$ ) plus transdermal nitroglycerin $(20 \mathrm{mg} / 24 \mathrm{~h})$ results in an enhanced fall in portal pressure and less marked systemic effects, and has been shown to be more effective and safer than vasopressin in randomized controlled trials (RCTs) and meta-analyses [46]. It is still used in countries were neither terlipressin nor somatostatin are available. 


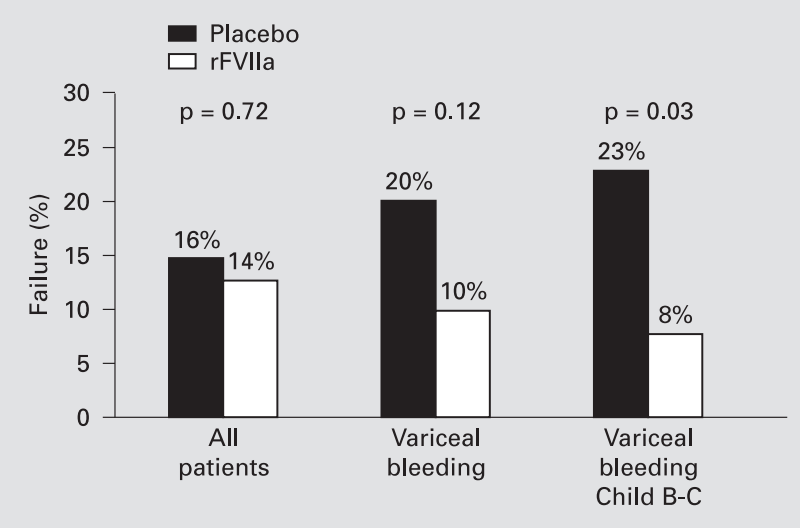

Fig. 2. Effects of recombinant factor VIIa on gastrointestinal bleeding in patients with cirrhosis. Treatment failure was defined as a composite end-point composed of the following 3 end-points: failure to control bleeding within $24 \mathrm{~h}$, or failure to prevent rebleeding between $24 \mathrm{~h}$ and 5 days, or death within 0-5 days. Overall there was no effect of the drug on treatment failure. However, an exploratory analysis of the subgroup of variceal bleeders with Child-Pugh scores B or C and more severe coagulopathy indicated that significantly fewer rFVIIa-treated patients than placebo-treated patients failed on the composite end-point. Constructed with data from Bosch et al. [45].

Terlipressin is a long-acting triglycyl lysine derivative of vasopressin. On top of its own vasoactive effects, terlipressin is slowly transformed to vasopressin by enzymatic cleavage of the triglycyl residues by tissue peptidases [47]. Clinical studies have consistently shown less frequent and less severe side effects with terlipressin than with vasopressin, even when vasopressin (alone or associated with nitroglycerin), and it has been speculated that this reduction may be related to the combination of high tissue concentrations with low circulating levels as a consequence of the slow release of vasopressin [47]. Terlipressin may be initiated as early as variceal bleeding is suspected at a dose of $2 \mathrm{mg} / 4 \mathrm{~h}$ for the first $48 \mathrm{~h}$, and it may be maintained for up to 5 days at a dose of $1 \mathrm{mg} / 4 \mathrm{~h}$ to prevent rebleeding [48]. Compared with placebo or non-active treatment, terlipressin significantly improves the control of bleeding and survival [49]. This is the only treatment that has been shown to improve the prognosis of variceal bleeding in placebo-controlled RCTs and meta-analyses [46, 49]. Terlipressin is as effective as any other effective therapy, including endoscopic injection sclerotherapy, and is safer than vasopressin + nitroglycerin and endoscopic injection sclerotherapy [46, 48, 49]. The overall efficacy of terlipressin in controlling acute variceal bleeding at $48 \mathrm{~h}$ is $75-80 \%$ across trials [49], and
$67 \%$ at 5 days [48]. Terlipressin is also useful in hepatorenal syndrome [50]. Thus the use of terlipressin for variceal bleeding may prevent renal failure, which is frequently precipitated by variceal bleeding [51]. F-180, another long-acting $\mathrm{V}_{1 \alpha}$-selective vasopressin analogue, has further been shown to prevent the increase in portal pressure caused by blood transfusion [52].

Somatostatin has been used for over two decades [53] in the treatment of acute variceal bleeding, based on its ability to decrease portal pressure and collateral blood flow [54]. The usual scheme for somatostatin administration is an initial bolus of $250 \mu \mathrm{g}$ followed by a $250-\mu \mathrm{g} / \mathrm{h}$ infusion that is maintained until the achievement of a 24-hour bleed-free period. Therapy may be further maintained for up to 5 days to prevent early rebleeding [55]. Very recently, the use of higher doses $(500 \mu \mathrm{g} / \mathrm{h})$ has been shown to translate into increased clinical efficacy in a subset of patients with more severe hemorrhage, pointed out by the finding of active bleeding at emergency endoscopy [56]. Several RCTs showed that somatostatin compared with placebo or nonactive treatment significantly improves the rate of control of bleeding [46, 57]. However, despite the beneficial effect on control of bleeding, somatostatin did not reduce mortality [46]. Somatostatin has been compared with terlipressin and no differences were found for failure to control bleeding, rebleeding and mortality. Side effects were similar in both treatment groups [46]. Major side effects with somatostatin are negligible.

Octreotide is a somatostatin analogue with a longer half-life. This, however, is not associated with longer hemodynamic effects than somatostatin [58]. The optimal doses are not well determined. It is usually given as an initial bolus of $50 \mu \mathrm{g}$, followed by an infusion of 25 or $50 \mu \mathrm{g} / \mathrm{h}$ [57]. As with somatostatin, therapy can be maintained for 5 days to prevent early rebleeding. The efficacy of octreotide as a single therapy for variceal bleeding is controversial. No benefit from octreotide was found in the only trial using octreotide or placebo as initial treatment [59], which may be due to rapid development of tachyphylaxis [58]. However, RCTs using octreotide on top of sclerotherapy or ligation have shown a significant benefit in terms of reducing early rebleeding [60]. It has been speculated that this may be related to its sustained ability to prevent a post-prandial increase in portal pressure [57]. Mortality, however, was not affected [46, 60]. These results suggest that octreotide may improve the results of endoscopic therapy but has no or little effect if used alone. When compared with other vasoactive drugs, octreotide was better than vasopressin and equivalent to 
terlipressin, again suggesting a clinical value from the use of octreotide [46]. Side effects were less frequent and severe with octreotide than with either vasopressin or terlipressin, but the difference was significant only for vasopressin [46].

\section{Drug Selection}

The decision depends on local resources. In general terms, terlipressin should be the first choice if available, since the results of double-blind RCT vs. placebo are more consistent than with other drugs and is the only shown to improve survival [61]. Somatostatin or octreotide are second choice [46, 57]. If these drugs are not available, vasopressin plus nitroglycerin is an acceptable option [46].

\section{Combined Medical Therapy}

The current recommended hemostatic treatment for variceal bleeding is to start on a vasoactive drug from admission, and to associate endoscopic therapy at the time of diagnostic endoscopy [62,63]. Drug therapy may be started during transferal to hospital by medical or paramedical teams [61] and maintained for up to 5 days to prevent early rebleeding [62]. With this approach, initial control of bleeding is about $75 \%$. The rationale for this combined treatment comes from a number of RCTs demonstrating that early administration of a vasoactive drug facilitates endoscopy and improves control of bleeding and 5-day rebleeding $[61,64,65]$. Drug therapy also improves the results of endoscopic treatment if started just after sclerotherapy or band ligation [46, 57, 60]. Moreover, the association of endoscopic therapy may improve the efficacy of vasoactive treatment [66]. However, this combined approach failed to improve 6-week mortality with respect to endoscopic therapy [67] or a vasoactive drug [66] alone. On the other hand, single vasoactive therapy is as effective as endoscopic therapy, but with significantly less side effects [68], which questions the use of endoscopic therapy as single treatment.

\section{Prevention of First Bleeding and of Rebleeding}

Continuous treatment to prevent variceal bleeding or rebleeding requires the use of orally active agents that reduce portal pressure. Nonselective $\beta$-adrenergic blockers are the most widely used drugs to treat portal hypertension. However, only $30-40 \%$ of the patients under longterm therapy reduce their portal pressure by $\geq 20 \%$ from baseline or to levels $\leq 12 \mathrm{~mm} \mathrm{Hg}$ [8]. Lack of achieve- ment of these hemodynamic targets constitutes the strongest independent predictor of variceal bleeding or rebleeding $[8,10]$, indicating that the available armamentarium to treat portal hypertension is far from optimal.

\section{Choice of $\beta$-Blocker}

This should be a nonselective one, acting both on $\beta_{1}$ cardiac receptors and $\beta_{2}$ vascular receptors. There appears to be no difference in the efficacy of propranolol and nadolol, the only nonselective $\beta$-adrenergic blockers tested in clinical trials [46]. In the authors' experience, intolerance to one may be overcome by shifting to the other. Nadolol may be more convenient since it is administered once a day, and due to its low-lipid solubility may have lower potential for central side effects [69]. Timolol has also low liposolubility [69], and has the greatest $\beta_{2^{-}}$ adrenoceptor-blocking effect [70].

\section{Dose Adjustment}

The dose of $\beta$-adrenergic blockers is determined by stepwise increases in dose until reaching the maximum tolerated. This approach is probably more effective than titrating against heart rate to achieve a reduction of about $25 \%[14]$.

\section{Contraindications and Intolerance}

Up to $15-20 \%$ of the cirrhotic patients with varices present contraindications that preclude the use of $\beta$ blockers, and an additional 5\% develop intolerance to the treatment that results in treatment withdrawal [71].

\section{Combination with Vasodilating Agents}

The rationale underlying this approach is that some patients do not respond to propranolol due to an increase in porto-systemic collateral (and, maybe, intrahepatic) resistance [72, 73], hindering the reduction in portal pressure. Indeed, the addition of isosorbide mononitrate (ISMN) has been shown to significantly increase the longterm response to $\beta$-adrenergic blockers [74, 75] without adverse effects on renal function [76, 77]. It is not clear, however, that this approach improves the clinical results of $\beta$-adrenergic blockers alone.

\section{Prevention of First Bleeding from Esophageal Varices}

A total of 12 trials assessing $\beta$-adrenergic blockers for the prevention of first bleeding have been conducted. Meta-analysis of these studies shows that continued pro- 
pranolol or nadolol therapy markedly reduces the bleeding risk, from $25 \%$ with nonactive treatment to $15 \%$ with $\beta$-adrenergic blockers [46] over a median follow-up of 2 years. Mortality was only slightly reduced from 27 to $23 \%$; this effect barely approached the level of statistical significance. The benefit of therapy has been proved in patients with moderate/large varices $(>5 \mathrm{~mm})$, either with or without ascites or with good or poor liver function [46, 78]. A recent trial demonstrated that beta-blockers reduce the rate of progression from small to large varices, and decrease the incidence of variceal bleeding in patients with small varices. Although confirmatory double-blinded trials are required, this suggests that the indication of $\beta$-blockers could be extended to patients with small varices [79]. Therapy with $\beta$-adrenergic blockers should be maintained indefinitely, since when these are withdrawn the risk of variceal hemorrhage returns to what would be expected in an untreated population [80].

A question still debated is whether the greater portal pressure-reducing effect of the combination of $\beta$-blockers + nitrates on portal pressure translates into greater clinical efficacy. An open trial comparing nadolol with nadolol + ISMN demonstrated a significant lower rate of first bleeding in the combination group, that was maintained after 55 months of follow-up, without a survival advantage [81, 82]. However, a large, randomized, double-blind study failed to confirm these results [71]. Current consensus does not recommend combination therapy in primary prophylaxis [62].

About 15-20\% of patients are excluded from therapy with $\beta$-adrenergic blockers in clinical practice because of relative or absolute contraindications [46, 83]. In this case, treatment with ISMN, despite its mild portal pressure-lowering effect, was ineffective in a double-blind placebo-controlled clinical trial [83]. Variceal band ligation is also effective and may be an alternative to $\beta$-blockers for primary prophylaxis, especially in those patients with contraindications or intolerance to $\beta$-blockers [84].

\section{Prevention of Recurrent Bleeding from Esophageal Varices}

Because of the extremely high risk of rebleeding in untreated patients, all patients surviving a variceal bleeding should receive urgent and active treatments for the prevention of rebleeding $[62,85,86]$. In addition, those with poor liver function or other recurrent complications of portal hypertension should be considered for liver transplantation.

Variceal Bleeding: Pharmacological Therapy
Either pharmacological treatment with $\beta$-adrenergic blockers or variceal band ligation are accepted first-line treatments to prevent rebleeding. Pharmacological treatment is based on the use of non-selective $\beta$-adrenergic blockers [87]. Meta-analyses consistently found a marked benefit from $\beta$-adrenergic blockers, both in terms of rebleeding (from $63 \%$ in controls to $42 \%$ under $\beta$-adrenergic blockers) and mortality (from 27 to 20\%) [46]. Again, controversy exists on whether to add nitrates. Two trials are available $[88,89]$, one of them double-blind and placebo-controlled, but only available in abstract form [88]. These studies failed to consistently show a benefit from combination therapy in terms of rebleeding or survival. $\beta$-Adrenergic blockers + nitrates combination therapy has been recommended on the basis of its superiority over sclerotherapy or band ligation $[11,12]$. The authors recommend to evaluate, whenever possible, the hemodynamic response to $\beta$-adrenergic blockers. If a $20 \%$ decrease in HVPG or to $\leq 12 \mathrm{~mm} \mathrm{Hg}$ is not achieved, ISMN may be added, which enables the target reduction in portal pressure to be achieved in a third of non-responders to $\beta$-blockers alone [90].

Since endoscopic therapy is also effective in preventing variceal rebleeding, the question arises on whether pharmacological treatment should be preferred to band ligation. This decision is obvious when there are contraindications to $\beta$-adrenergic blockers. In the absence of contraindications, no clear recommendations can be given, since the meta-analysis of the four available trials comparing optimal endoscopic treatment (band ligation) versus optimal pharmacological treatment (the combination of $\beta$-blockers + ISMN) [12, 91-93] shows comparable results with the two therapies (fig. 3). Patient preferences and local resources must be taken into account when making the choice [94]. The association of $\beta$-blockers and variceal band ligation has been shown to be better than variceal band ligation alone in one study [95]. Ongoing studies will confirm whether this combined approach is really better than variceal band ligation or drug therapy alone.

\section{Prevention of the Formation of Varices ('Pre-Primary' Prevention)}

Studies to explore whether long-term therapy with nonselective $\beta$-blockers may prevent or delay the development of varices and other complications of portal hypertension, such as ascites, in patients with compensated cirrhosis have been prompted by the results of studies

Dig Dis 2005;23:18-29 




Fig. 3. Meta-analysis of the available randomized controlled trials that compare optimal pharmacological treatment $(\beta$-blockers + nitrates) with optimal endoscopic treatment (endoscopic banding ligation) to prevent rebleeding. There were no differences between the two therapies in terms of variceal rebleeding and survival. In the trial by Romero et al. [92], low-volume sclerotherapy was added to banding ligation.

showing that: (a) development of porto-systemic collaterals is significantly lower in animals with experimental portal hypertension treated chronically with $\beta$-blockers than in controls [96]; (b) in patients with cirrhosis, varices decreased in size and may eventually disappear when HVPG is reduced below $12 \mathrm{~mm} \mathrm{Hg}[6,7]$, and (c) portal pressure (HVPG) reduction achieved by nonselective $\beta$ blockers is significantly greater in patients without varices than in those who already have developed esophageal varices, and most achieve or maintain an HVPG below $12 \mathrm{~mm} \mathrm{Hg}$ [73]. Despite this solid rationale, a recent large, multicenter, double-blind, randomized trial showed that long-term timolol administration was unable to prevent the development of varices in patients with compensated cirrhosis [97].

\section{New Drugs to Treat Portal Hypertension}

Nearly half of the patients treated with the combination of $\beta$-adrenergic blockers and nitrates do not achieve the target reduction in portal pressure $(>20 \%$ from the baseline or to $>12 \mathrm{~mm} \mathrm{Hg}$ ). Therefore, it is clear that there is room for improvement in the currently available armamentarium to treat portal hypertension. Theoretically, the ideal drug to treat patients with cirrhosis and portal hypertension should act by decreasing intrahepatic vascular resistance and portal pressure while maintaining or enhancing hepatic blood flow. To this aim the vasodilator effect of such a drug should be limited to the hepatic circulation to prevent further splanchnic/systemic vasodilatation and hypotension. However, such a drug is not currently available. The most recent developments in the search for new drugs for the treatment of portal hypertension are discussed below.

\section{Drugs That Decrease Hepatic Resistance}

Prazosin is an $\alpha_{1}$-adrenergic antagonist that markedly reduces HVPG in patients with cirrhosis. This reduction is associated with increased hepatic blood flow, suggesting a reduction in hepatic vascular resistance $[98,99]$. However, chronic prazosin administration was associated with a significant reduction in arterial pressure and systemic vascular resistance and activation of endogenous vasoactive systems leading to plasma volume expansion, sodium retention and in some cases, to the accumulation of ascites [99]. These findings discouraged its use in the treatment of portal hypertension. The adverse effects of prazosin on the systemic circulation and renal function are attenuated by the combined administration of prazosin and propranolol. More interesting, the association of propranolol and prazosin was significantly more effective, in terms of reducing HVPG, than the association of propranolol and ISMN [100]. This drug combination has not been assessed in RCTs.

\section{Renin-Angiotensin System Blockers}

Activation of the renin-angiotensin system is a frequent finding in patients with cirrhosis, especially in those with more advanced disease. Angiotensin II may act on hepatic circulation, increasing hepatic resistance and contributing to portal hypertension. Blockade of this system has been tested as another approach to treat portal hypertension. In a recent nonrandomized study in patients with portal hypertension, losartan, a nonpeptide 
antagonist of angiotensin-receptor type I, caused a dramatic reduction in portal pressure with only slight arterial hypotension and no significant adverse effects [101]. These impressive findings, however, were not confirmed in subsequent RCTs, in which angiotensin II blockade with irbesartan or losartan only had a slight or null effect on portal pressure, while it decreased arterial pressure and GFR [102-106]. These agents, clearly dangerous in advanced cirrhosis, seem to be ineffective in early cirrhosis as well [105].

\section{Endothelin Receptor Blockers}

Endothelin also increases hepatic resistance in cirrhosis. However, conflicting results have been obtained with endothelin blockers in experimental models of portal hypertension. Acute administration of the mixed ETA-ETB receptor blocker bosentan decreased portal pressure [107, 108], while chronic administration of RO 48-5695, a second-generation mixed ET-receptor blocker, did not modify portal pressure and even increased liver fibrosis [109]. In contrast, chronic selective blockade of ETA receptor with LU 135252 dramatically decreased collagen accumulation in rats with secondary biliary cirrhosis [110], while acute administration of another ETA blocker (FR 139317) to cirrhotic rats did not lower portal pressure [111]. In humans, preliminary data show that neither ETA nor ET-B blockers reduce portal pressure, and that ETA blockers are potentially dangerous since they induce arterial hypotension [112].

\section{Selective Hepatic Delivery of NO}

It is increasingly recognized that insufficient availability of NO in the hepatic circulation is implicated in the increase in hepatic vascular tone as well as in fibrogenesis [113] and local thrombotic phenomena that may contribute to the progression of cirrhosis [114]. This suggests that prolonged administration of orally active hepatic NO donors could both modify the dynamic component of increased intrahepatic resistance and ameliorate fibrosis, and delay the progression of cirrhosis. However, in patients with advanced cirrhosis the use of non-liver-selective NO donors, such as ISMN, enhances peripheral vasodilation, further decreasing arterial blood pressure and activating endogenous vasoactive systems. So far, the administration of ISMN has proven clinically ineffective in terms of prevention of variceal bleeding [83, 115-117].

Liver-specific NO donors are being investigated. These agents would be devoid of systemic vasodilator effects, and thus will be close to the attributes of the ideal drug for the treatment of portal hypertension. The drug that has shown more promising results in experimental studies is NCX-1000, an NO-releasing derivative of ursodeoxycholic acid [118]. NCX-1000 has been shown to reduce hepatic resistance in two different models of cirrhosis [118-120], without affecting systemic hemodynamics. There are no data on the effects of this drug in patients with cirrhosis.

Another potential approach is to enhance NO production in the liver by drugs that enhance endogenous eNOS activity. In that regard, a recent study has shown that simvastatin, a lipid-lowering agent that also increases NO production by upregulating eNOS, acutely decreases hepatic vascular resistance in patients with cirrhosis, without inducing hypotension [121]. A randomized study to evaluate the hemodynamic effects of the continuous administration of this drug in cirrhosis is under way.

\section{Drugs That Decrease Splanchnic Blood Flow}

The great amount of information gathered on the mechanism of splanchnic vasodilation and increased portal inflow in cirrhosis $[19,122]$ has not translated yet in any therapeutic benefit for patients with portal hypertension. 'Old' drugs such as $\beta$-adrenergic blockers, vasopressin and somatostatin and their respective derivatives remain the only used vasoconstrictors in clinical practice. Vasoconstrictors have other advantages in advanced cirrhosis, since they improve renal function and the hyperdynamic state $[50,123,124]$. These drugs, however, by decreasing portal inflow may impair liver function.

Available data on the effects of systemic NO blockade in patients with cirrhosis are still insufficient. A very recent report showed that systemic administration of the NOS inhibitor $\mathrm{N}^{\mathrm{G}}$-monomethyl- $L$-arginine ( $L$-NMMA) to patients with cirrhosis and portal hypertension corrected systemic hemodynamics and improved renal function and sodium excretion [125]. However, as observed in the experimental setting [33] and in cirrhotic patients in a previous report with the same drug [126], the increase in hepatic resistance caused by NO inhibition results in no decrease in portal pressure despite the fall in portal blood flow. This is probably due to the fact that intrahepatic NO, although insufficient, still plays a major role in regulating hepatic vascular tone. Furthermore, hepatic NO production, even if reduced, may still be protective and delay the progression of cirrhosis. 


\section{Drugs That Decrease Hepatic Resistance and Portal Blood Inflow}

Carvedilol: this drug combines a nonselective $\beta$-blocker action with an $\alpha_{1}$-adrenoceptor blocking activity and, thus, mimics the effects of the combination therapy of propranolol/nadolol plus prazosin, which causes a very pronounced decrease in portal pressure but is associated with excessive hypotension [100]. In a recent study, the acute administration of carvedilol induced a marked decrease in portal pressure gradient that was significantly greater than that achieved by propranolol, despite causing similar reductions in splanchnic blood flow [127]. This suggests that carvedilol decreases hepatic and/or porto-systemic collateral resistance due to its anti $\alpha_{1}$-ad- renergic activity. However, studies evaluating its longterm effects showed discrepant results. In one study, a $25-\mathrm{mg} /$ day dose of carvedilol was associated with marked hypotension leading to discontinuation of the treatment in a significant proportion of patients [128]. Subsequent studies showed that lower doses (12.5 mg/day) [129] or careful titration [130] result in good tolerance, maintaining the portal hypotensive effect $[129,130]$. Indeed, when compared with propranolol in a randomized trial [130], carvedilol increased significantly the number of patients [54 vs. $23 \%$ ] achieving a target reduction in HVPG (of $\geq 20 \%$ from baseline or below $12 \mathrm{~mm} \mathrm{Hg}$ ). This drug should be further evaluated in randomized trials with clinical end-points.

\section{References}

-1 Groszmann RJ, Glickman M, Blei AT, Storer E, Conn HO: Wedged and free hepatic venous pressure measured with a balloon catheter. Gastroenterology 1979;76:253-258.

-2 Perello A, Escorsell A, Bru C, Gilabert R, Moitinho E, Garcia-Pagan JC, Bosch J: Wedged hepatic venous pressure adequately reflects portal pressure in hepatitis $\mathrm{C}$ virus-related cirrhosis. Hepatology 1999;30:13931397.

-3 Wongcharatrawee S, Groszmann RJ: Diagnosing portal hypertension. Baillieres Best Pract Res Clin Gastroenterol 2000;14:881-894.

-4 Viallet A, Marleau D, Huet M, Martin F, Farley A, Villeneuve JP, Lavoie P: Hemodynamic evaluation of patients with intrahepatic portal hypertension. Relationship between bleeding varices and the portohepatic gradient. Gastroenterology 1975;69:1297-1300.

\5 Garcia-Tsao G, Groszmann RJ, Fisher RL, Conn HO, Atterbury CE, Glickman M: Portal pressure, presence of gastroesophageal varices and variceal bleeding. Hepatology 1985; 5: 419-424.

6 Casado M, Bosch J, Garcia-Pagan JC, Bru C, Banares R, Bandi JC, et al: Clinical events after transjugular intrahepatic portosystemic shunt: Correlation with hemodynamic findings. Gastroenterology 1998;114:1296-1303.

-7 Groszmann RJ, Bosch J, Grace ND, Conn HO, Garcia-Tsao G, Navasa M, et al: Hemodynamic events in a prospective randomized trial of propranolol versus placebo in the prevention of a first variceal hemorrhage (see comments). Gastroenterology 1990;99:1401-1407.

- 8 Feu F, Garcia-Pagan JC, Bosch J, Luca A, Teres J, Escorsell A, Rodes J: Relation between portal pressure response to pharmacotherapy and risk of recurrent variceal haemorrhage in patients with cirrhosis. Lancet 1995;346: 1056-1059.
9 Vorobioff J, Groszmann RJ, Picabea E, Gamen M, Villavicencio R, Bordato J, et al: Prognostic value of hepatic venous pressure gradient measurements in alcoholic cirrhosis: A 10-year prospective study. Gastroenterology 1996;111:701-709.

10 Merkel C, Bolognesi M, Sacerdoti D, Bombonato G, Bellini B, Bighin R, Gatta A: The hemodynamic response to medical treatment of portal hypertension as a predictor of clinical effectiveness in the primary prophylaxis of variceal bleeding in cirrhosis. Hepatology 2000; 32:930-934.

11 Villanueva C, Balanzo J, Novella MT, Soriano G, Sainz S, Torras X, et al: Nadolol plus isosorbide mononitrate compared with sclerotherapy for the prevention of variceal rebleeding. N Engl J Med 1996;334:1624-1629.

12 Villanueva C, Minana J, Ortiz J, Gallego A, Soriano G, Torras X, et al: Endoscopic ligation compared with combined treatment with nadolol and isosorbide mononitrate to prevent recurrent variceal bleeding. N Engl J Med 2001; 345:647-655.

13 Escorsell A, Bordas JM, Castaneda B, Llach J, Garcia-Pagan JC, Rodes J, Bosch J: Predictive value of the variceal pressure response to continued pharmacological therapy in patients with cirrhosis and portal hypertension. Hepatology 2000;31:1061-1067.

14 Abraldes JG, Tarantino I, Turnes J, GarciaPagan JC, Rodes J, Bosch J: Hemodynamic response to pharmacological treatment of portal hypertension and long-term prognosis of cirrhosis. Hepatology 2003;37:902-908.

15 Villanueva C, Lopez-Balaguer JM, Aracil C, Kolle L, Gonzalez B, Minana J, et al: Maintenance of hemodynamic response to treatment for portal hypertension and influence on complications of cirrhosis. J Hepatol 2004; 40:757765.
16 Monescillo A, Martinez-Lagares F, Ruiz-delArbol L, Sierra A, Guevara C, Jimenez E, et al: Influence of portal hypertension and its early decompression by TIPS placement on the outcome of variceal bleeding. Hepatology 2004; 40:793-801.

17 Moitinho E, Escorsell A, Bandi JC, Salmeron JM, Garcia-Pagan JC, Rodes J, Bosch J: Prognostic value of early measurements of portal pressure in acute variceal bleeding. Gastroenterology 1999;117:626-631.

18 Villanueva C, Ortiz J, Minana J, Soriano G, Sabat M, Boadas J, Balanzo J: Somatostatin treatment and risk stratification by continuous portal pressure monitoring during acute variceal bleeding. Gastroenterology 2001;121: 110-117.

19 Wiest R, Groszmann RJ: The paradox of nitric oxide in cirrhosis and portal hypertension: Too much, not enough. Hepatology 2002;35:478491.

20 Pinzani M, Gentilini P: Biology of hepatic stellate cells and their possible relevance in the pathogenesis of portal hypertension in cirrhosis. Semin Liver Dis 1999;19:397-410.

21 Rockey DC, Weisiger RA: Endothelin induced contractility of stellate cells from normal and cirrhotic rat liver: Implications for regulation of portal pressure and resistance. Hepatology 1996;24:233-240.

22 Ballet F, Chretien Y, Rey C, Poupon R: Differential response of normal and cirrhotic liver to vasoactive agents. A study in the isolated perfused rat liver. J Pharmacol Exp Ther 1988; 244:233-235.

23 Graupera M, García-Pagán JC, GonzalezAbraldes J, Bosch J, Rodes J: Cirrhotic livers exhibit a hyperresponse to methoxamine. Role of nitric oxide and eicosanoids. J Hepatol 2001;34:66A 
-24 Graupera M, Garcia-Pagan JC, Titos E, Claria J, Massaguer A, Bosch J, Rodes J: 5-lipoxygenase inhibition reduces intrahepatic vascular resistance of cirrhotic rat livers: A possible role of cysteinyl-leukotrienes. Gastroenterology 2002;122:387-393.

-25 Bathal PS, Grossmann HJ: Reduction of the increased portal vascular resistance of the isolated perfused cirrhotic rat liver by vasodilators. J Hepatol 1985; 1:325-329.

-26 Marteau P, Ballet F, Chazouilleres O, Chretien Y, Rey C, Petit D, Poupon R: Effect of vasodilators on hepatic microcirculation in cirrhosis: A study in the isolated perfused rat liver. Hepatology 1989;9:820-823.

27 Reichen J, Le M: Verapamil favorably influences hepatic microvascular exchange and function in rats with cirrhosis of the liver. J Clin Invest 1986; 78:448-455.

-28 Gupta TK, Toruner M, Chung MK, Groszmann RJ: Endothelial dysfunction and decreased production of nitric oxide in the intrahepatic microcirculation of cirrhotic rats. Hepatology 1998;28:926-931.

-29 Rockey DC, Chung JJ: Reduced nitric oxide production by endothelial cells in cirrhotic rat liver: Endothelial dysfunction in portal hypertension. Gastroenterology 1998;114:344-351.

- 30 Vorobioff J, Bredfeldt J, Groszmann RJ: Hyperdynamic circulation in a portal hypertensive rat model: A primary factor for maintenance of chronic portal hypertension. Am J Physiol 1983;244:G52-G56.

31 Benoit JN, Barrowman JA, Harper SL, Kvietys PR, Granger DN: Role of humoral factors in the intestinal hyperemia associated with chronic portal hypertension. Am J Physiol 1984;247: G486-G493.

32 Pizcueta MP, Piqué JM, Bosch J, Whittle BJR, Moncada S: Effects of inhibiting nitric oxide biosynthesis on the systemic and splanchnic circulation of rats with portal hypertension. $\mathrm{Br}$ J Pharmacol 1992;105:105-184.

- 33 Pizcueta P, Piqué JM, Fernández M, Bosch J, Rodés J, Whittle BJR, Moncada S: Modulation of the hyperdynamic circulation of cirrhotic rats by nitric oxide inhibition. Gastroenterology 1992;103:1909-1915.

- 34 Wiest R, Groszmann RJ: Nitric oxide and portal hypertension: Its role in the regulation of intrahepatic and splanchnic vascular resistance. Semin Liver Dis 1999;19:411-426.

- 35 Schrier RW, Arroyo V, Bernardi M, Epstein M, Henriksen JH, Rodes J: Peripheral arterial vasodilation hypothesis: A proposal for the initiation of renal sodium and water retention in cirrhosis. Hepatology 1988;8:1151-1157.

-36 Groszmann RJ: Hyperdynamic circulation of liver disease 40 years later: Pathophysiology and clinical consequences (editorial; comment). Hepatology 1994;20:1359-1363.

- 37 Garcia-Pagan JC, Salmeron JM, Feu F, Luca A, Gines P, Pizcueta P, et al: Effects of low-sodium diet and spironolactone on portal pressure in patients with compensated cirrhosis. Hepatology 1994;19:1095-1099.
Garcia-Pagan JC, Escorsell A, Moitinho E, Bosch J: Influence of pharmacological agents on portal hemodynamics: Basis for its use in the treatment of portal hypertension. Semin Liver Dis 1999;19:427-438.

- 39 Goulis J, Armonis A, Patch D, Sabin C, Greenslade L, Burroughs AK: Bacterial infection is independently associated with failure to control bleeding in cirrhotic patients with gastrointestinal hemorrhage. Hepatology 1998; 27:1207-1212.

40 Vivas S, Rodriguez M, Palacio MA, Linares A, Alonso JL, Rodrigo L: Presence of bacterial infection in bleeding cirrhotic patients is independently associated with early mortality and failure to control bleeding. Dig Dis Sci 2001; 46:2752-2757.

$\checkmark 41$ Hou MC, Lin HC, Liu TT, Kuo BI, Lee FY, Chang FY, Lee SD: Antibiotic prophylaxis after endoscopic therapy prevents rebleeding in acute variceal hemorrhage: A randomized trial. Hepatology 2004;39:746-753.

-42 Bernard B, Grange JD, Khac EN, Amiot X, Opolon P, Poynard T: Antibiotic prophylaxis for the prevention of bacterial infections in cirrhotic patients with gastrointestinal bleeding: A meta-analysis. Hepatology 1999;29:16551661.

43 Rimola A, Garcia-Tsao G, Navasa M, Piddock LJ, Planas R, Bernard B, Inadomi JM: Diagnosis, treatment and prophylaxis of spontaneous bacterial peritonitis: A consensus document. International Ascites Club. J Hepatol 2000;32:142-153.

44 Bernstein DE, Jeffers L, Erhardtsen E, Reddy KR, Glazer S, Squiban P, et al: Recombinant factor VIIa corrects prothrombin time in cirrhotic patients: A preliminary study. Gastroenterology 1997;113:1930-1937.

45 Bosch J, Thabut D, Bendtsen F, D’Amico G, Albillos A, Gonzalez AJ, et al: Recombinant factor VIIa for upper gastrointestinal bleeding in patients with cirrhosis: A randomized, double-blind trial. Gastroenterology 2004;127: 1123-1130.

46 D’Amico G, Pagliaro L, Bosch J: Pharmacological treatment of portal hypertension: An evidence-based approach. Semin Liver Dis 1999; 19:475-505.

47 Bosch J, Lebrec D, Jenkins SA: Development of analogues: Successes and failures. Scand $\mathbf{J}$ Gastroenterol 1998;226(suppl):3-13.

48 Escorsell A, Ruiz dA, Planas R, Albillos A, Banares R, Cales $\mathrm{P}$ et al: Multicenter randomized controlled trial of terlipressin versus sclerotherapy in the treatment of acute variceal bleeding: the TEST study. Hepatology 2000;32:471-476.

49 Ioannou GN, Doust J, Rockey DC: Systematic review: Terlipressin in acute oesophageal variceal haemorrhage. Aliment Pharmacol Ther 2003; 17:53-64.

50 Uriz J, Gines P, Cardenas A, Sort P, Jimenez W, Salmeron JM, et al: Terlipressin plus albumin infusion: An effective and safe therapy of hepatorenal syndrome. J Hepatol 2000;33:4348.
51 Cardenas A, Gines P, Uriz J, Bessa X, Salmeron JM, Mas A, et al: Renal failure after upper gastrointestinal bleeding in cirrhosis: incidence, clinical course, predictive factors, and short-term prognosis. Hepatology 2001;34: 671-676.

52 Morales J, Moitinho E, Abraldes JG, Fernan$\operatorname{dez} \mathrm{M}$, Bosch J: Effects of the V1a vasopressin agonist F-180 on portal hypertension-related bleeding in portal hypertensive rats. Hepatology 2003;38:1378-1383.

- 53 Tyden G, Sammegard H, Thulin L, Friman L, Efendic S: Treatment of bleeding esophageal varices with somatostatin. N Engl J Med 1978; 299:1466-1467.

54 Bosch J, Kravetz D, Rodes J: Effects of somatostatin on hepatic and systemic hemodynamics in patients with cirrhosis of the liver: Comparison with vasopressin. Gastroenterology 1981;80:518-525.

-55 Escorsell A, Bordas JM, del Arbol LR, Jaramillo JL, Planas R, Banares R, et al: Randomized controlled trial of sclerotherapy versus somatostatin infusion in the prevention of early rebleeding following acute variceal hemorrhage in patients with cirrhosis. Variceal Bleeding Study Group. J Hepatol 1998;29:779-788.

-56 Moitinho E, Planas R, Bañares R, Albillos A, Ruiz-del-Arbol L, Galvez C, et al: Multicenter randomized controlled trial comparing different schedules of somatostatin in the treatment of acute variceal bleeding. J Hepatol 2001;35: 712-718.

-57 Abraldes JG, Bosch J: Somatostatin and analogues in portal hypertension. Hepatology 2002;35:1305-1312.

58 Escorsell A, Bandi JC, Andreu V, Moitinho E, Garcia-Pagan JC, Bosch J, Rodes J: Desensitization to the effects of intravenous octreotide in cirrhotic patients with portal hypertension. Gastroenterology 2001;120:161-169.

59 International Octreotide Varices Study Group, Burroughs AK: Double blind RCT of 5 day octreotide versus placebo, associated with sclerotherapy for trial failures. Hepatology 1996;24: $352 \mathrm{~A}$.

60 Corley DA, Cello JP, Adkisson W, Ko WF, Kerlikowske K: Octreotide for acute esophageal variceal bleeding: a meta-analysis. Gastroenterology 2001;120:946-954.

61 Levacher S, Letoumelin P, Pateron D, Blaise M, Lapandry C, Pourriat JL: Early administration of terlipressin plus glyceryl trinitrate to control active upper gastrointestinal bleeding in cirrhotic patients. Lancet 1995;346:865868.

62 de Franchis R: Updating consensus in portal hypertension: Report of the Baveno III Consensus Workshop on definitions, methodology and therapeutic strategies in portal hypertension. J Hepatol 2000;33:846-852.

63 Burroughs AK, Patch DW: Management of variceal haemorrhage in cirrhotic patients. Gut 2001;48:738-740. 
64 Avgerinos A, Nevens F, Raptis S, Fevery J: Early administration of somatostatin and efficacy of sclerotherapy in acute oesophageal variceal bleeds: The European Acute Bleeding Oesophageal Variceal Episodes (ABOVE) randomised trial. Lancet 1997;350:1495-1499.

-65 Cales P, Masliah C, Bernard B, Garnier PP, Silvain C, Szostak-Talbodec N, et al: Early administration of vapreotide for variceal bleeding in patients with cirrhosis. French Club for the Study of Portal Hypertension. N Engl J Med 2001;344:23-28.

-66 Villanueva C, Ortiz J, Sabat M, Gallego A, Torras X, Soriano G, et al: Somatostatin alone or combined with emergency sclerotherapy in the treatment of acute esophageal variceal bleeding: A prospective randomized trial. Hepatology 1999;30:384-389.

-67 Banares R, Albillos A, Rincon D, Alonso S, Gonzalez M, Ruiz-del-Arbol L, et al: Endoscopic treatment versus endoscopic plus pharmacologic treatment for acute variceal bleeding: A meta-analysis. Hepatology 2002;35: 609-615.

-68 D’Amico G, Pietrosi G, Tarantino I, Pagliaro L: Emergency sclerotherapy versus vasoactive drugs for variceal bleeding in cirrhosis: A Cochrane meta-analysis. Gastroenterology 2003; 124:1277-1291.

-69 Gengo FM, Huntoon L, McHugh WB: Lipidsoluble and water-soluble beta-blockers. Comparison of the central nervous system depressant effect. Arch Intern Med 1987;147: 39-43.

-70 Wang T, Kaumann AJ, Brown MJ: (-)-Timolol is a more potent antagonist of the positive inotropic effects of (-)-adrenaline than of those of (-)-noradrenaline in human atrium. Br J Clin Pharmacol 1996;42:217-223.

-71 Garcia-Pagan J, Morillas RM, Bañares R, Albillos A, Villanueva C, Vila C, et al: Propranolol plus placebo vs propranolol plus isosorbide5 -mononitrate in the prevention of the first variceal bleed. A double blind RCT. Hepatology 2003;37:1260-1266.

-72 Kroeger RJ, Groszmann RJ: Increased portal venous resistance hinders portal pressure reduction during the administration of beta-adrenergic blocking agents in a portal hypertensive model. Hepatology 1985;5:97-101.

-73 Escorsell A, Ferayorni L, Bosch J, Garcia-Pagan JC, Garcia-Tsao G, Grace ND, et al: The portal pressure response to beta-blockade is greater in cirrhotic patients without varices than in those with varices. Gastroenterology 1997;112:2012-2016

74 Garcia-Pagan JC, Feu F, Bosch J, Rodes J: Propranolol compared with propranolol plus isosorbide-5-mononitrate for portal hypertension in cirrhosis. A randomized controlled study. Ann Intern Med 1991;114:869-873.

-75 Merkel C, Sacerdoti D, Bolognesi M, Enzo E, Marin R, Bombonato G, et al: Hemodynamic evaluation of the addition of isosorbide-5mononitrate to nadolol in cirrhotic patients with insufficient response to the beta-blocker alone. Hepatology 1997;26:34-39.
76 Morillas RM, Planas R, Cabre E, Galan A, Quer JC, Feu F, et al: Propranolol plus isosorbide-5-mononitrate for portal hypertension in cirrhosis: long-term hemodynamic and renal effects. Hepatology 1994;20:1502-1508.

77 Merkel C, Gatta A, Donada C, Enzo E, Marin $\mathrm{R}$, Amodio P, et al: Long-term effect of nadolol or nadolol plus isosorbide-5-mononitrate on renal function and ascites formation in patients with cirrhosis. GTIP Gruppo Triveneto per l'Ipertensione Portale. Hepatology 1995; 22:808-813.

78 Poynard T, Cales P, Pasta L, Ideo G, Pascal JP, Pagliaro L, Lebrec D: Beta-adrenergic-antagonist drugs in the prevention of gastrointestinal bleeding in patients with cirrhosis and esophageal varices. An analysis of data and prognostic factors in 589 patients from four randomized clinical trials. Franco-Italian Multicenter Study Group. N Engl J Med 1991;324:1532_ 1538.

79 Merkel C, Marin R, Angeli P, Zanella P, Felder $\mathrm{M}$, Bernardinello E, et al: A placebo-controlled clinical trial of nadolol in the prophylaxis of growth of small esophageal varices in cirrhosis. Gastroenterology 2004;127:476-484.

80 Abraczinskas DR, Ookubo R, Grace ND, Groszmann RJ, Bosch J, Garcia-Tsao G, et al: Propranolol for the prevention of first esophageal variceal hemorrhage: A lifetime commitment? Hepatology 2001;34:1096-1102.

81 Merkel C, Marin R, Enzo E, Donada C, Cavallarin G, Torboli P, et al: Randomised trial of nadolol alone or with isosorbide mononitrate for primary prophylaxis of variceal bleeding in cirrhosis. Gruppo Triveneto per l'Ipertensione Portale (GTIP) (see comments). Lancet 1996; 348:1677-1681.

82 Merkel C, Marin R, Sacerdoti D, Donada C, Cavallarin G, Torboli P, et al: Long-term results of a clinical trial of nadolol with or without isosorbide mononitrate for primary prophylaxis of variceal bleeding in cirrhosis. Hepatology 2000; 31: 324-329.

83 Garcia-Pagan JC, Villanueva C, Vila MC, Albillos A, Genesca J, Ruiz-del-Arbol L et al: Isosorbide mononitrate in the prevention of first variceal bleed in patients who cannot receive beta-blockers. Gastroenterology 2001;121: 908-914.

84 Schepke M, Kleber G, Nurnberg D, Willert J, Koch L, Veltzke-Schlieker W, et al: Ligation versus propranolol for the primary prophylaxis of variceal bleeding in cirrhosis. Hepatology 2004; 40:65-72.

85 D'Amico G, Pagliaro L, Bosch J: The treatment of portal hypertension: A meta-analytic review. Hepatology 1995;22:332-354.

86 Grace ND, Groszmann RJ, Garcia-Tsao G, Burroughs AK, Pagliaro L, Makuch RW, et al: Portal hypertension and variceal bleeding: an AASLD single topic symposium. Hepatology 1998;28:868-880.

87 Lebrec D, Nouel O, Bernuau J, Bouygues M, Rueff B, Benhamou JP: Propranolol in prevention of recurrent gastrointestinal bleeding in cirrhotic patients. Lancet 1981;i:920-921.
88 Pasta L, D’Amico G, Patti R: Isosorbide mononitrate (IMN) with nadolol compared with nadolol alone for prevention of recurrent bleeding in cirrhosis. A double-blind placebocontrolled randomised trial. J Hepatol 1999; 30:81A.

-89 Gournay J, Masliah C, Martin T, Perrin D, Galmiche JP: Isosorbide mononitrate and propranolol compared with propranolol alone for the prevention of variceal rebleeding. Hepatology 2000;31:1239-1245.

90 Bureau C, Peron JM, Alric L, Morales J, Sanchez J, Barange K, et al: 'A la carte' treatment of portal hypertension: Adapting medical therapy to hemodynamic response for the prevention of bleeding. Hepatology 2002;36:13611366.

91 Patch D, Sabin CA, Goulis J, Gerunda G, Greenslade L, Merkel C, Burroughs AK: A randomized, controlled trial of medical therapy versus endoscopic ligation for the prevention of variceal rebleeding in patients with cirrhosis. Gastroenterology 2002;123:1013-1019.

92 Romero G, Kravetz D, Argonz J, Vulcano C, Suarez A, Fassio E, et al: Nadolol plus isosorbide mononitrate compared with banding plus low volume sclerotherapy for prevention of variceal rebleeding in patients with cirrhosis. Hepatology 2004; 40 (suppl 1):204A.

-93 Lo GH, Chen WC, Chen MH, Hsu PI, Lin CK, Tsai WL, Lai KH: Banding ligation versus nadolol and isosorbide mononitrate for the prevention of esophageal variceal rebleeding. Gastroenterology 2002;123:728-734.

94 Groszmann RJ, Garcia-Tsao G: Endoscopic variceal banding vs. pharmacological therapy for the prevention of recurrent variceal hemorrhage: What makes the difference? Gastroenterology 2002;123:1388-1391.

95 Lo GH, Lai KH, Cheng JS, Chen MH, Huang HC, Hsu PI, Lin CK: Endoscopic variceal ligation plus nadolol and sucralfate compared with ligation alone for the prevention of variceal rebleeding: A prospective, randomized trial. Hepatology 2000;32:461-465.

96 Sarin SK, Groszmann RJ, Mosca PG, Rojkind M, Stadecker MJ, Bhatnagar R, et al: Propranolol ameliorates the development of portal-systemic shunting in a chronic murine schistosomiasis model of portal hypertension. J Clin Invest 1991;87:1032-1036.

-97 Groszmann RJ, Garcia-Tsao G, Makuch R, Bosch J, Escorsell A, Garcia-Pagan JC, et al: Multicenter, randomized placebo-controlled trial of non-selective beta-blockers in the prevention of the complications of portal hypertension: Final results and identification of a predictive factor. Hepatology 2003;38(suppl 1):206A.

98 Albillos A, Lledo JL, Banares R, Rossi I, Iborra J, Calleja JL, et al: Hemodynamic effects of alpha-adrenergic blockade with prazosin in cirrhotic patients with portal hypertension. Hepatology 1994;20:611-617. 
$>99$ Albillos A, Lledo JL, Rossi I, Perez-Paramo M, Tabuenca MJ, Banares R, et al: Continuous prazosin administration in cirrhotic patients: Effects on portal hemodynamics and on liver and renal function. Gastroenterology 1995; 109:1257-1265.

$>100$ Albillos A, Garcia-Pagan JC, Iborra J, Bandi JC, Cacho G, Perez-Paramo M, et al: Propranolol plus prazosin compared with propranolol plus isosorbide-5-mononitrate in the treatment of portal hypertension. Gastroenterology 1998;115:116-123.

-101 Schneider AW, Friedrich J, Klein CP: Effect of losartan, an angiotensin II receptor antagonist, on portal pressure in cirrhosis. Hepatology 1999;29:334-339.

- 102 Schepke M, Werner E, Biecker E, Schiedermaier P, Heller J, Neef M, et al: Hemodynamic effects of the angiotensin II receptor antagonist irbesartan in patients with cirrhosis and portal hypertension. Gastroenterology 2001;121:389-395.

-103 Gonzalez-Abraldes J, Albillos A, Banares R, del Arbol LR, Moitinho E, Rodriguez C, et al: Randomized comparison of long-term losartan versus propranolol in lowering portal pressure in cirrhosis. Gastroenterology 2001; 121:382-388.

- 104 Debernardi-Venon W, Barletti C, Alessandria C, Marzano A, Baronio M, Todros L, et al: Efficacy of irbesartan, a receptor selective antagonist of angiotensin II, in reducing portal hypertension. Dig Dis Sci 2002;47:401404.

105 Tripathi D, Therapondos G, Lui HF, Johnston N, Webb DJ, Hayes PC: Chronic administration of losartan, an angiotensin II receptor antagonist, is not effective in reducing portal pressure in patients with preascitic cirrhosis. Am J Gastroenterol 2004;99:390394.

106 Venon WD, Baronio M, Leone N, Rolfo E, Fadda M, Barletti C, et al: Effects of longterm Irbesartan in reducing portal pressure in cirrhotic patients: Comparison with propranolol in a randomised controlled study. $\mathrm{J}$ Hepatol 2003;38:455-460.

$\checkmark 107$ Reichen J, Gerbes AL, Steiner MJ, Sagesser H, Clozel M: The effect of endothelin and its antagonist Bosentan on hemodynamics and microvascular exchange in cirrhotic rat liver. J Hepatol 1998;28:1020-1030.

108 Sogni P, Moreau R, Gomola A, Gadano A, Cailmail S, Calmus Y, et al: Beneficial hemodynamic effects of bosentan, a mixed ET(A) and ET(B) receptor antagonist, in portal hypertensive rats. Hepatology 1998;28:655659.

109 Poo JL, Jimenez W, Maria MR, Bosch-Marce M, Bordas N, Morales-Ruiz M, et al: Chronic blockade of endothelin receptors in cirrhotic rats. Hepatic and hemodynamic effects. Gastroenterology 1999;116:161-167.
110 Cho JJ, Hocher B, Herbst H, Jia JD, Ruehl M, Hahn EG, et al: An oral endothelin-A receptor antagonist blocks collagen synthesis and deposition in advanced rat liver fibrosis. Gastroenterology 2000;118:1169-1178.

111 Kojima H, Sakurai S, Kuriyama S, Yoshiji H, Imazu H, Uemura M, et al: Endothelin-1 plays a major role in portal hypertension of biliary cirrhotic rats through endothelin receptor subtype B together with subtype A in vivo. J Hepatol 2001;34:805-811.

112 Therapondos G, Ferguson JW, Newby DE, Webb DJ, Hayes P: Endothelin-1 contributes to the maintenance of systemic hemodynamics in patients with cirrhosis: A double-blind randomized controlled hemodynamic study. Hepatology 2004;40(suppl 1):185A.

113 Failli P, DeFranco RM, Caligiuri A, Gentilini A, Romanelli RG, Marra F, et al: Nitrovasodilators inhibit platelet-derived growth factor-induced proliferation and migration of activated human hepatic stellate cells. Gastroenterology 2000;119:479-492.

114 Wanless IR, Wong F, Blendis LM, Greig P, Heathcote EJ, Levy G: Hepatic and portal vein thrombosis in cirrhosis: Possible role in development of parenchymal extinction and portal hypertension. Hepatology 1995;21: 1238-1247.

115 Angelico M, Carli L, Piat C, Gentile S, Capocaccia L: Effects of isosorbide-5-mononitrate compared with propranolol on first bleeding and long-term survival in cirrhosis (see comments). Gastroenterology 1997;113: 1632-1639.

116 Borroni G, Salerno F, Cazzaniga M, Bissoli F, Lorenzano E, Maggi A, et al: Nadolol is superior to isosorbide mononitrate for the prevention of the first variceal bleeding in cirrhotic patients with ascites. J Hepatol 2002; $37: 315$.

117 Lui HF, Stanley AJ, Forrest EH, Jalan R, Hislop WS, Mills PR, et al: Primary prophylaxis of variceal hemorrhage: A randomized controlled trial comparing band ligation, propranolol, and isosorbide mononitrate. Gastroenterology 2002;123:735-744.

118 Fiorucci S, Antonelli E, Morelli O, Mencarelli A, Casini A, Mello T, et al: NCX-1000, a NO-releasing derivative of ursodeoxycholic acid, selectively delivers NO to the liver and protects against development of portal hypertension. Proc Natl Acad Sci USA 2001;98: 8897-8902.

119 Loureiro-Silva MR, Cadelina G, Iwakiri Y, Groszmann RJ: A liver-specific nitric oxide donor improves the intra-hepatic vascular response to both portal blood flow increase and methoxamine in cirrhotic rats. J Hepatol, in press.
120 Fiorucci S, Antonelli E, Brancaleone V, Sanpaolo L, Orlandi S, Distrutti E, et al: NCX1000, a nitric oxide-releasing derivative of ursodeoxycholic acid, ameliorates portal hypertension and lowers norepinephrine-induced intrahepatic resistance in the isolated and perfused rat liver. J Hepatol 2003;39: 932-939.

121 Zafra C, Abraldes JG, Turnes J, Berzigotti A, Fernandez M, Garca-Pagan JC, et al: Simvastatin enhances hepatic nitric oxide production and decreases the hepatic vascular tone in patients with cirrhosis. Gastroenterology 2004; 126:749-755.

122 Bosch J, Garcia-Pagan JC: Complications of cirrhosis. I. Portal hypertension. J Hepatol 2000;32:141-156.

123 Guevara M, Gines P, Fernandez-Esparrach G, Sort P, Salmeron JM, Jimenez W, et al: Reversibility of hepatorenal syndrome by prolonged administration of ornipressin and plasma volume expansion. Hepatology 1998; 27:35-41.

124 Angeli P, Volpin R, Gerunda G, Craighero R, Roner P, Merenda R, et al: Reversal of type 1 hepatorenal syndrome with the administration of midodrine and octreotide. Hepatology 1999;29:1690-1697.

125 La Villa G, Barletta G, Pantaleo P, Del Bene R, Vizzutti F, Vecchiarino S, et al: Hemodynamic, renal, and endocrine effects of acute inhibition of nitric oxide synthase in compensated cirrhosis. Hepatology 2001;34:19-27.

126 Forrest EH, Jones AL, Dillon JF, Walker J, Hayes PC: The effect of nitric oxide synthase inhibition on portal pressure and azygos blood flow in patients with cirrhosis. J Hepatol 1995;23:254-258.

127 Banares R, Moitinho E, Piqueras B, Casado M, Garcia-Pagan JC, de Diego A, Bosch J: Carvedilol, a new nonselective beta-blocker with intrinsic anti-alpha-1-adrenergic activity, has a greater portal hypotensive effect than propranolol in patients with cirrhosis (see comments). Hepatology 1999;30:79-83.

128 Stanley AJ, Therapondos G, Helmy A, Hayes PC: Acute and chronic haemodynamic and renal effects of carvedilol in patients with cirrhosis. J Hepatol 1999;30:479-484.

129 Tripathi D, Therapondos G, Lui HF, Stanley AJ, Hayes PC: Haemodynamic effects of acute and chronic administration of low-dose carvedilol, a vasodilating beta-blocker, in patients with cirrhosis and portal hypertension. Aliment Pharmacol Ther 2002;16:373-380.

130 Banares R, Moitinho E, Matilla A, GarciaPagan JC, Lampreave JL, Piera C, et al: Randomized comparison of long-term carvedilol and propranolol administration in the treatment of portal hypertension in cirrhosis. Hepatology 2002;36:1367-1373. 